\title{
Synthesis and polymerization of perfluoroalkylated 3,4-propylenedioxythiophene
}

\author{
Jian-Hai Dong ${ }^{\mathrm{a}}$, Wei-Dong Meng ${ }^{\mathrm{a}}$, and Feng-Ling Qing $^{\mathrm{a}}{ }^{\mathrm{b}} *$ \\ ${ }^{a}$ College of Chemistry and Chemical Engineering, Donghua University, 1882 West Yanan Road, \\ Shanghai 200051, China \\ ${ }^{b}$ Key Laboratory of Organofluorine Chemistry, Shanghai Institute of Organic Chemistry, \\ Chinese Academy of Sciences, 354 Fenglin Lu, Shanghai 200032, China
}

Fax: 86-21-64166128

E-mail: flq@pub.sioc.ac.cn

\section{Dedicated to Professor Chengye Yuan on the occasion of his $8^{\text {th }}$ birthday}

(received 30 Dec 03; accepted 02 Mar 04; published on the web 14 May 04)

\begin{abstract}
A novel monomer, perfluoroalkylated 3,4-propylenedioxythiophene, was prepared by transetherification reaction between 3,4-dimethoxythiophene and perfluoroalkylated cycloalkylpropane-1,3-diol. Bromination of monomer followed by a Grignard metathesis coupling reaction provided perfluoroalkylated poly(3,4-propylenedioxythiophene). This polymer was quite insoluble in any known solvent.
\end{abstract}

Keywords: Polythiophenes, perfluoroalkylation

\section{Introduction}

Polythiophenes have been extensively investigated as one of the most important classes of conjugated polymers. ${ }^{1-3}$ In order to improve the property of polythiophene, numerous substituted derivatives of polythiophenes have been developed that carry alkyl, alkoxy, and other substituents along their backbones. Among them, poly(3,4-ethylenedioxythiophene) (PEDOT) has attracted significant attention, ${ }^{4}$ both in academic as well as in industrial labs, because of its high electrochromic contrast, low oxidation potential, better stability to air exposure at ambient and elevated temperature conditions, and faster switching speeds. Recently, Reynolds and coworkers have studied the effect of ring size on the electrochromic properties of polymers based on 3,4-alkylenedioxythiophene, and they observed that the electrochromic contrast improves on increasing the ring size and also on increasing the interchain separation by the incorporation of a 
rigid/bulky side chain. ${ }^{5}$ From then on, a number of polymers with high contrast based on substituted 3,4-propylenedioxythiophene have been prepared. ${ }^{6-8}$

Fluorinated polymers have attracted attention because of their unusual properties, which are the consequences of the hydrophobicity, rigidity, thermal stability, chemical and oxidative resistance, and self-organization of perfluoroalkyl chains. ${ }^{9}$ A number of 3-semifluorinated alkylsubstituted polythiophenes have been prepared for controlling molecular architecture and improving environmental stability. ${ }^{10-13}$

In the light of the above facts, we envisaged that poly(3,4-propylenedioxythiophene), which contains a perfluoroalkyl chain, should possess high electrochromic contrast and thermal stability. We describe herein the synthesis of perfluoroalkylated poly(3,4propylenedioxythiophene).

\section{Results and Discussion}

Our initial attempts to prepare monomer 1 (Figure 1) were hindered, because the perfluoroalkylation of diethyl 2,2-diallylmalonate $\mathbf{3}$ failed to furnish compound $\mathbf{4}$ and only gave the cyclized product 5 (Scheme 1). Then we turned our attention to synthesize monomer 2 (Figure 1).

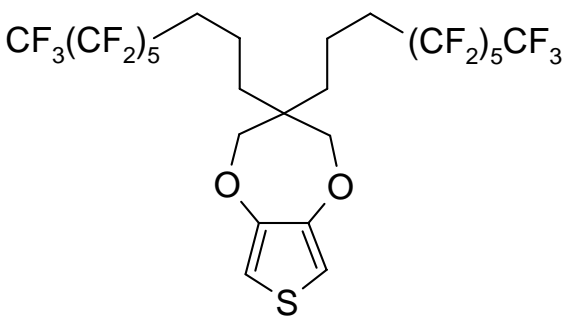

1

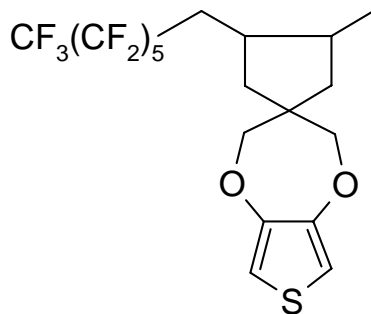

2

\section{Figure 1}

The monomer 2 was synthesized in 65\% yield by a transetherification reaction between 3,4dimethoxythiophene and $\mathbf{6}$ as shown in Scheme 1. Methanol was removed from the reaction mixture with a Soxhlet extractor filled with type 4A molecular sieves in order to drive the reaction to completion. 3,4-Dimethoxythiophene was prepared according to the literature procedures. ${ }^{14}$ Compound 5 was synthesized starting from diethyl malonate (Scheme 1). Diethyl 2,2-diallylmalonate 3 was obtained in $61 \%$ yield by the reaction of diethyl malonate with allyl bromide under NaOEt-EtOH conditions. When compound $\mathbf{3}$ was treated with 1iodoperfluorohexane at $70^{\circ} \mathrm{C}$ using AIBN as initiator, the reaction afforded not product 4 , but the cyclized product 5 in $63 \%$ yield. Reduction of 5 with lithium aluminium hydride in THF at reflux gave compound $\mathbf{6}$ in 74\% yield. 


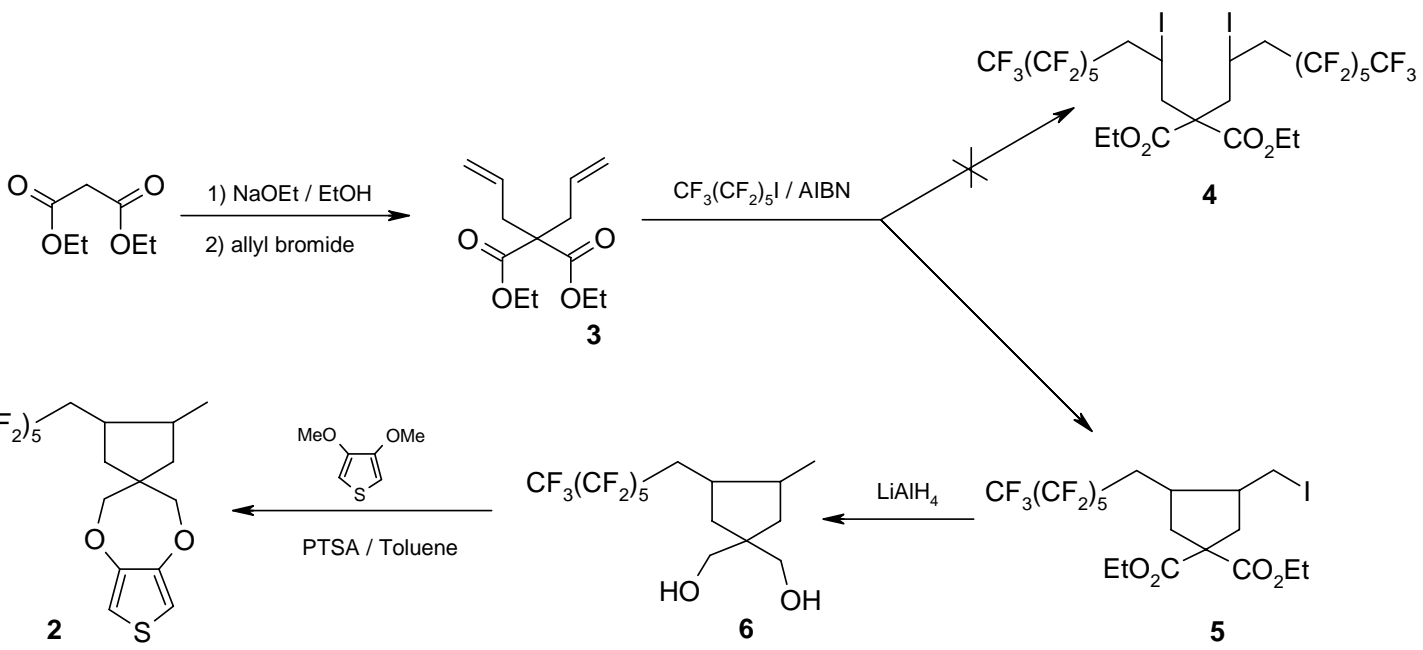

\section{Scheme 1}

Compound 2 was successfully brominated with addition of excess $N$-bromosuccinimide (NBS) to yield 2,5-dibromo-substituted thiophene 7 as a solid in $87 \%$ yield (Scheme 2), which could be purified by flash column chromatography. Following the Grignard metathesis procedure developed by McCullough and co-workers, ${ }^{15}$ compound 7 was treated with freshly prepared ethylmagnesium bromide at reflux followed by addition of $\mathrm{Ni}(\mathrm{dppp}) \mathrm{Cl}_{2}$ to yield corresponding polymer 8 as a dark purple solid. The polymer was purified by Soxhlet extraction with methanol and hexanes to remove low molecular weight and inorganic impurities. As polymer 8 was quite insoluble in any known solvent, its chemical characterization and properties studies were difficult. The main characterization was realized by elemental analysis and IR spectra.

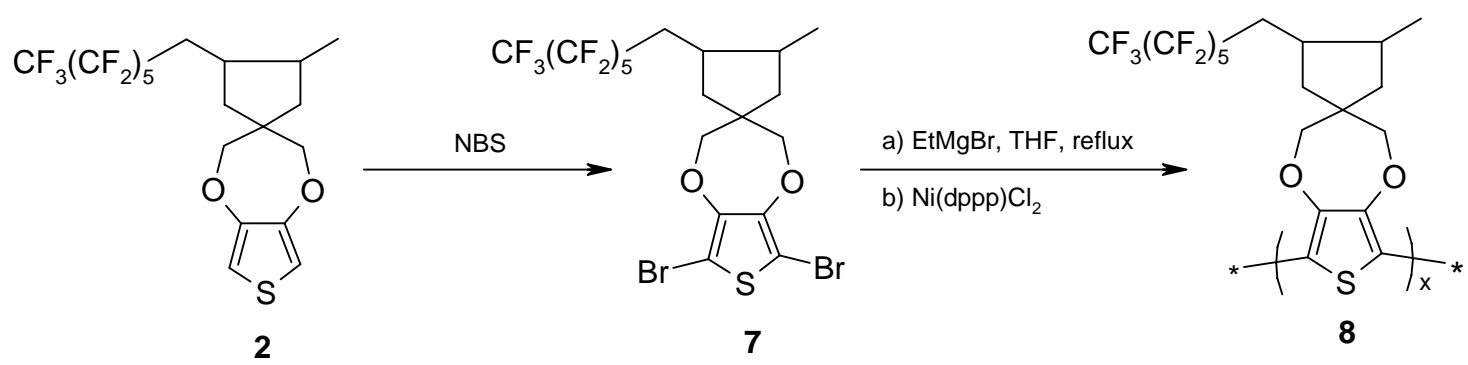

\section{Scheme 2}

\section{Experimental Section}

General Procedures. ${ }^{1} \mathrm{H}$ NMR spectra were recorded on a Bruker AM $300(300 \mathrm{MHz})$ spectrometer with $\mathrm{Me}_{4} \mathrm{Si}$ as internal standard. ${ }^{19} \mathrm{~F}$ NMR spectra were obtained on Bruker AM $300(282 \mathrm{MHz})$ spectrometer in $\mathrm{CDCl}_{3}$ with $\mathrm{CFCl}_{3}$ as external standard, downfield shifts being 
designated as negative. All chemical shifts $(\delta)$ are expressed in ppm, coupling constants $(J)$ are given in Hz. Mass spectra were recorded on a Finnigan-MAT-8430 instrument using EI ionization at $70 \mathrm{eV}$. IR spectra were recorded on a Shimadzu IR-440 spectrometer.

Diethyl 2,2-diallylmalonate (3). Sodium (18 g, $0.78 \mathrm{~mol})$ was added in small portions to $150 \mathrm{~mL}$ absolute ethanol and then the reaction mixture was refluxed for $1 \mathrm{~h}$. Diethyl malonate ( $48 \mathrm{~g}, 0.3 \mathrm{~mol}$ ) was added slowly to the prepared sodium ethoxide solution. Then allyl bromide (73 g, $0.6 \mathrm{~mol}$ ) was added dropwise to the mixture at room temperature. After the reaction mixture was refluxed for $3 \mathrm{~h}, 500 \mathrm{~mL}$ water was added and mixture was neutralized to $\mathrm{pH}=7$ with $2 \mathrm{~N} \mathrm{HCl}$. The organic layer was separated and the water layer was extracted with ether. The combined organic layer was washed water, dried over anhydrous $\mathrm{MgSO}_{4}$, concentrated and distilled to yield $43.8 \mathrm{~g}$ of $3\left(61 \%\right.$ yield, bp $\left.89-90^{\circ} \mathrm{C} / 2 \mathrm{mmHg}\right) .{ }^{1} \mathrm{H}$ NMR $(\mathrm{CDCl} 3) \delta: 1.25$ (t, $6 \mathrm{H}, J$ $=7.0 \mathrm{~Hz}), 2.65(\mathrm{~d}, 4 \mathrm{H}, J=7.0 \mathrm{~Hz}), 4.20(\mathrm{q}, 4 \mathrm{H}, J=7.0 \mathrm{~Hz}), 5.12-5.65(\mathrm{~m}, 6 \mathrm{H})$.

3-Iodomethyl-4-(2,2,3,3,4,4,5,5,6,6,7,7,7-tridecafluoroheptyl)cyclopentane-1,1-dicarboxylic acid diethyl ester (5). Under a nitrogen atmosphere, a mixture of diethyl 2,2-diallylmalonate 3 $(12.0 \mathrm{~g}, 50 \mathrm{mmol})$, perflourohexyl iodide $(44.6 \mathrm{~g}, 100 \mathrm{mmol})$ and AIBN $(0.164 \mathrm{~g}, 1 \mathrm{mmol})$ was stirred at $70^{\circ} \mathrm{C}$ for $5 \mathrm{~h}$. The crude mixture was subjected to a flash column chromatography to give compound $5(21.6 \mathrm{~g}, 63.0 \%$ yield $)$ as colorless clear liquid. ${ }^{1} \mathrm{H}$ NMR $\left(\mathrm{CDCl}_{3}\right) \delta: 1.26(\mathrm{t}, 6 \mathrm{H}$, $J=7.0 \mathrm{~Hz}), 1.84-2.40(\mathrm{~m}, 6 \mathrm{H}), 2.57(\mathrm{q}, 1 \mathrm{H}), 2.77(\mathrm{q}, 1 \mathrm{H}), 3.13-3.37(\mathrm{~m}, 2 \mathrm{H}), 4.21(\mathrm{q}, 4 \mathrm{H}, J=$ 7.0Hz); ${ }^{19} \mathrm{~F} \mathrm{NMR}\left(\mathrm{CDCl}_{3}\right) \delta$ : -94.4 (s, 3F), -124.7--127.9 (m, 2F), -135.4 (s, 2F), -136.5 (s, 2F), 137.0 (s, 2F), -139.8 (s, 2F); MS (m/z): $686\left(\mathrm{M}^{+}, 1\right), 559$ (100), 485 (76), 411 (75), 413 (71), 79 (36); IR $\left(\mathrm{cm}^{-1}\right): 2986,1730,1242,1197,1145,812,732,707,655,533$; Anal. Calcd. for $\mathrm{C}_{19} \mathrm{H}_{20} \mathrm{~F}_{13} \mathrm{IO}_{4}$ : C, 33.24; $\mathrm{H}, 2.92$. Found: $\mathrm{C}, 33.57 ; \mathrm{H}, 2.94 \%$.

\section{[1-Hydroxymethyl-3-methyl-4(2,2,3,3,4,4,5,5,6,6,7,7,7-tridecafluoroheptyl)cyclopentyl]-}

methanol (6). A solution of compound $5(20.6 \mathrm{~g}, 30 \mathrm{mmol})$ in dry THF $(50 \mathrm{~mL})$ was added slowly to a solution of lithium aluminium hydride $(3.5 \mathrm{~g}, 90 \mathrm{mmol})$ in dry THF $(100 \mathrm{~mL})$ under a nitrogen atmosphere. The mixture was stirred at reflux for $4 \mathrm{~h}$ and then was cooled to room temperature. Water was added. The organic extracts were separated and the water layer was extracted with ether. The combined organic extracts were washed with water, dried over anhydrous $\mathrm{MgSO}_{4}$. The solvent was removed in vacuo. The resulting residue was purified by recrystallization from ethanol to give compound $\mathbf{6}(10.6 \mathrm{~g}, 74 \%$ yield $)$ as a white solid.

${ }^{1} \mathrm{H}$ NMR $\left(\mathrm{CDCl}_{3}\right) \delta: 0.90(\mathrm{~d}, 3 \mathrm{H}, J=7.0 \mathrm{~Hz}), 1.24-1.42(\mathrm{~m}, 4 \mathrm{H}), 1.66(\mathrm{q}, 1 \mathrm{H}, J=7.0 \mathrm{~Hz}), 1.87(\mathrm{~m}$, $1 \mathrm{H}), 1.97(\mathrm{~s}, 2 \mathrm{H}), 2.25-2.41(\mathrm{~m}, 2 \mathrm{H}), 3.59(\mathrm{~s}, 2 \mathrm{H}), 3.68(\mathrm{~s}, 2 \mathrm{H}) ;{ }^{19} \mathrm{~F} \mathrm{NMR}\left(\mathrm{CDCl}_{3}\right) \delta:-94.3(\mathrm{~s}$, 3F), -126.3--127.7 (m, 2F), -135.3 (s, 2F), -136.4 (s, 2F), -137.1 (s, 2F), -139.6 (s, 2F); ${ }^{13} \mathrm{C}$ NMR $\left(\mathrm{CD}_{3} \mathrm{SOCD}_{3}\right) \delta: 130.0,122.5,119.0,115.0,112.0,107.0,66.6,65.9,47.7,38.4,36.0,35.6,34.2$, 30.2, 15.5; MS (m/z): 458 (M-18), 440 (M-36), 427 (100), 428 (66), 413 (60), 95 (15); IR $\left(\mathrm{cm}^{-1}\right)$ : 3364, 2936, 2872, 1247, 1210, 1144, 1041, 705, 657; Anal. Calcd for $\mathrm{C}_{15} \mathrm{H}_{17} \mathrm{~F}_{13} \mathrm{O}_{2}: \mathrm{C}, 37.82 ; \mathrm{H}$, 3.57. Found: C, $37.82 ; \mathrm{H}, 3.46 \%$. 
3,3-[3-Methyl-4(2,2,3,3,4,4,5,5,6,6,7,7,7-tridecafluoroheptyl)cyclopentyl]-3,4-dihydro-2Hthieno[3,4-b]-[1,4]dioxepine (2). 3,4-Dimethoxythiophene (1.44 g, $10 \mathrm{mmol})$, compound 6 (4.76 g, $10 \mathrm{mmol})$, p-toluenesulfonic acid $(0.2 \mathrm{~g})$ and toluene $(200 \mathrm{~mL})$ were combined in a twoneck flask equipped with a Soxhlet extractor with type $4 \mathrm{~A}$ molecular sieves in the thimble. The mixture was heated to reflux for $24 \mathrm{~h}$. The reaction mixture was cooled and washed with water, dried over anhydrous $\mathrm{MgSO}_{4}$ and concentrated. The crude product was purified with a flash column chromatography to give monomer $2\left(3.6 \mathrm{~g}, 65 \%\right.$ yield) as a white powder. ${ }^{1} \mathrm{H}$ NMR $\left(\mathrm{CDCl}_{3}\right) \delta: 0.96(\mathrm{~d}, 3 \mathrm{H}, J=7.0 \mathrm{~Hz}), 1.37-1.54(\mathrm{~m}, 2 \mathrm{H}), 1.73(\mathrm{q}, 1 \mathrm{H}, J=7.0 \mathrm{~Hz}), 1.99-2.43(\mathrm{~m}$, 5H), 3.71-3.94 (m, 4H), $6.48(\mathrm{~s}, 2 \mathrm{H}) ;{ }^{19} \mathrm{~F} \mathrm{NMR}\left(\mathrm{CDCl}_{3}\right) \delta$ : -94.3 (s, 3F), -124.3--128.7 (m, 2F), $135.3(\mathrm{~s}, 2 \mathrm{~F}),-136.4(\mathrm{~s}, 2 \mathrm{~F}),-137.1$ (s, 2F), -139.7 (s, 2F); MS (m/z): $556\left(\mathrm{M}^{+}, 28\right), 116(100)$, 441 (64), 399 (25), 55 (24), 107 (23); IR ( $\left.\mathrm{cm}^{-1}\right)$ : 3109, 2970, 2866, 1489, 1372, 1237, 1195, 1145, 1018, 848, 784, 709, 657; Anal. Calcd. for $\mathrm{C}_{19} \mathrm{H}_{17} \mathrm{~F}_{13} \mathrm{O}_{2} \mathrm{~S}$ : C, 41.01; H, 3.06. Found: C, $41.09 ; \mathrm{H}, 3.02 \%$.

6,8-Dibromo-3,3-[3-methyl-4(2,2,3,3,4,4,5,5,6,6,7,7,7-tridecafluoroheptyl)cyclopentyl]-3,4dihydro-2H-thieno[3,4-b]-[1,4]dioxepine (7). A solution of monomer 2 (2.066 g, $3.7 \mathrm{mmol})$ in $\mathrm{CHCl}_{3}(100 \mathrm{~mL})$ was bubbled with nitrogen for $30 \mathrm{~min}$. NBS $(2.0 \mathrm{~g}, 11.1 \mathrm{mmol})$ was added. The reaction mixture was stirred at room temperature for $4 \mathrm{~h}$. The solvent was removed in vacuo. The resulting residue was purified with a flash column chromatography to give compound 7 (2.311 g, $88 \%$ yield) as a dust-color solid. ${ }^{1} \mathrm{H}$ NMR $\left(\mathrm{CDCl}_{3}\right) \delta: 0.96(\mathrm{~d}, 3 \mathrm{H}, J=7.0 \mathrm{~Hz}), 1.41 \sim 1.53(\mathrm{~m}$, 2H), $1.73(\mathrm{q}, 1 \mathrm{H}, J=7.0 \mathrm{~Hz}), 2.00-2.44(\mathrm{~m}, 5 \mathrm{H}), 3.83-4.05(\mathrm{~m}, 4 \mathrm{H}) ;{ }^{19} \mathrm{~F} \mathrm{NMR}\left(\mathrm{CDCl}_{3}\right) \delta:-94.4$ $(\mathrm{s}, 3 \mathrm{~F}),-124.8-128.7(\mathrm{~m}, 2 \mathrm{~F}),-135.4(\mathrm{~s}, 2 \mathrm{~F}),-136.5(\mathrm{~s}, 2 \mathrm{~F}),-137.2$ (s, 2F), -139.7 (s, 2F); MS $(\mathrm{m} / \mathrm{z}): 712\left(\mathrm{M}^{+}, 12\right), 714\left(\mathrm{M}^{+}+2,24\right), 716\left(\mathrm{M}^{+}+4,13\right), 441$ (100), 274 (68), 399 (36), 276 (35), 272 (35); IR $\left(\mathrm{cm}^{-1}\right):$ 2972, 2868, 1576, 1502, 1353, 1254, 1200, 1145, 1064, 846, 708, 692, 657; Anal. Calcd. for $\mathrm{C}_{19} \mathrm{H}_{15} \mathrm{Br}_{2} \mathrm{~F}_{13} \mathrm{O}_{2} \mathrm{~S}$ : C, 31.93; H, 2.10. Found: C, 31.99; H, 2.14\%.

Polymer 8. Under a nitrogen atmosphere and at room temperature, the solution of ethyl bromide $(0.36 \mathrm{~g}, 3.3 \mathrm{mmol})$ in dry THF $(10 \mathrm{~mL})$ was added dropwise to a mixture of magnesium $(0.080$ $\mathrm{g}, 3.3 \mathrm{mmol})$ and dry THF $(10 \mathrm{~mL})$. After the addition, the reaction mixture was stirred at reflux for $1 \mathrm{~h}$. Under a nitrogen atmosphere, the ethyl magnesium bromide solution was transferred to a dropping funnel and then was slowly added to a solution of compound 7 (2.3 $\mathrm{g}, 3.25 \mathrm{mmol})$ in dry THF $(20 \mathrm{~mL})$. The mixture was stirred at reflux for $1 \mathrm{~h}$. Then $\mathrm{Ni}(\mathrm{dppp}) \mathrm{Cl}_{2}(0.035 \mathrm{~g})$ was added. The reaction mixture was stirred at reflux for $24 \mathrm{~h}$. The polymer was precipitated from $200 \mathrm{~mL}$ of methanol and filtered into a Soxhlet thimble. Soxhlet extractions were performed for $24 \mathrm{~h}$ with methanol and $48 \mathrm{~h}$ with hexanes to yield polymer 8 (0.305 g, 13\% yield) as a dark purple solid. IR (cm $\left.{ }^{-1}\right)$ : 2959, 1471, 1436, 1367, 1239, 1206, 1145, 1121, 1038, 846, 812, 783, 732, 707, 659; Elemental Analysis (\%): Calculated for a chain taking into account the bromine content found and assuming one bromine and one hydrogen as end groups: Anal. Calcd for $\mathrm{C}_{19} \mathrm{H}_{15} \mathrm{~F}_{13} \mathrm{O}_{2} \mathrm{~S}$ : C, 41.16; H, 2.71. Found: $\mathrm{C}, 40.33 ; \mathrm{H}, 2.73$. The deviation of experimental analysis from calculated is explained by the presence of some terminal $\mathrm{Br}$ atoms in polymer. 


\section{References}

1. Fichou, D.; Eds.; Handbook of Oligo- and Polythiophenes; Wiley-VCH: Weinheim, 1999, p 1.

2. Katz, H. E.; Bao, Z. N.; Gilat, S. L. Acc. Chem. Res. 2001, 34, 359.

3. Fichou, D. J. Mater. Chem. 2000, 10, 578.

4. Groenendaal, L. B.; Jonas, F.; Freitag, D.; Pielartzik, H.; Reynolds, J. R. Adv. Mater. 2000, $12,481$.

5. Kumar, A.; Welsh, D. M.; Morvant, M. C.; Piroux, F.; Abboud, K. A.; Reynolds, J. R. Chem. Mater. 1998, 10, 896.

6. Welsh, D. M.; Kumar, A.; Meijer, E. W.; Reynolds, J. R. Adv. Mater. 1999, 11, 1379.

7. Krishnamoorthy, K.; Ambade, A. V.; Kanungo, M.; Contractor, A. Q.; Kumar, A. J. Mater. Chem. 2001, 11, 2909.

8. Welsh, D. M.; Kloeppner, L. J.; Madrigal, L.; Pinto, M. R.; Thompson, B. C.; Schanze, K. S.; Abboud, K. A.; Powell, D.; Reynolds, J. R. Macromolecules 2002, 35, 6517.

9. Schmiegel, W. W.; Chemistry of Organic Fluorine Compounds II: A Critical Review, Hudlicky, M. A.; Pavlath, E. Eds.; ACS Monograph 187; American Chemical Society: Washington, DC, 1995, p 1101.

10. Buchner, W.; Garreau, R.; Lemaire, M.; Roncali, J.; Garnier, F. J. Electroanal. Chem. 1990, 277, 355.

11. Hong, X.Y.; Tyson, J. C.; Middlecoff, J. S.; Collard, D. M. Macromolecules 1999, 32, 4232.

12. Hong, X.Y.; Tyson, J. C.; Collard, D. M. Macromolecules 2000, 33, 3502.

13. Hong, X.Y.; Collard, D. M. Macromolecules 2000, 33, 6916.

14. Keegstra, M. A.; Peters, T. H. A.; Brandsma, L. Tetrahedron 1992, 48, 3633.

15. McCullough, R. D.; Lowe, R. D.; Jayaraman, M.; Anderson, D. L. J. Org. Chem. 1993, 58, 904. 